\title{
Comparison of three methods for the detection of Epstein-Barr virus in Hodgkin's lymphoma in paraffin-embedded tissues
}

\author{
ZONG-LI QI $^{1,2}$, XI-QUN HAN ${ }^{3}$, JUN HU ${ }^{1,2}$, GUANG-HUA WANG ${ }^{1,2}$, \\ JIN-WEI GAO ${ }^{1,2}$, XIN WANG $^{1,2}$ and DAO-YAN LIANG ${ }^{1,2}$ \\ ${ }^{1}$ Laboratory Center, Shaanxi Provincial People's Hospital, Xi'an, Shaanxi; ${ }^{2}$ The Third Affiliated Hospital, \\ Xi'an Jiaotong University, Xi'an; ${ }^{3}$ Department of Pathology, Nangfang Medical University, Guangdong, P.R. China
}

Received June 26, 2012; Accepted October 16, 2012

DOI: $10.3892 / \mathrm{mmr} .2012 .1163$

\begin{abstract}
The percentage rate of Epstein-Barr virus (EBV)positive cases of Hodgkin's lymphoma (HL) ranges between 20 and $70 \%$ in various studies worldwide. To further explore the definite rate in China, three methods, including immunohistochemistry for EBV latent membrane protein 1 (LMP1), in situ hybridization (ISH) for EBV-encoded RNA (EBER)-1 and polymerase chain reaction (PCR) for EBV BamHI-W fragment, were employed to detect EBV in 59 cases of HL in China using paraffin-embedded tissue samples. Our results revealed that the PCR method presented the highest (44/59, $74.6 \%$ ) detection rate among the three methods. The other two methods identified 66.1\% (39/59, LMP1) and 67.8\% (40/59, EBER1 ISH) EBV-positive results, respectively. Three samples were positive for LMP1 but negative when using EBER1 ISH, while another four samples were EBER1-positive but LMP1negative. Of the four major histopathological subtypes of HL, the lymphocyte predominant (LR) subtype is the one most frequently associated with EBV, followed by the mixed cellularity (MC), nodular sclerosis (NS) and lymphocyte depletion (LD) subtypes. Our results also indicated the seldomly reported fact that EBV-positive cases in children were more numerous than those of adults with HL.
\end{abstract}

\section{Introduction}

Substantial evidence implicates the Epstein-Barr virus (EBV) in the pathogenesis of Hodgkin's lymphoma (HL) (1-3). EBV detection in HL may be used to risk-stratify patients and derive optimum treatment strategies. Investigation into the presence of EBV nucleic acids in affected tissues in EBV-associated diseases is performed by a variety of different techniques, including spot hybridization, in situ hybridization (ISH) and the

Correspondence to: Dr Zongli Qi, Laboratory Center, Shaanxi Provincial People's Hospital, 256 West Youyi Road, Xi'an, Shaanxi 710068, P.R. China

E-mail: qizongli@126.com

Key words: Epstein-Barr virus, Hodgkin's lymphoma, latent membrane protein 1, EBV encoded RNA-1, polymerase chain reaction polymerase chain reaction $(\mathrm{PCR})(2,3)$. EBV-related proteins, including EBV nuclear antigen 1 (EBNA1) and the latent membrane proteins (LMP1, LMP2a and LMP2b) have also been examined by performing immunohistochemical assays. As previously stated, the percentage of EBV-positive cases of HL varied among studies, ranging between 20 and $70 \%$ (1), and one of the most significant causes for this wide range may be the sensitivity of the method employed. To obtain an accurate percentage for the EBV infection rate in China, three different EBV detecting methods were employed to analyse 59 paraffinembedded tissue samples from national cases of HL.

\section{Materials and methods}

Materials and samples. In total, 59 formalin-fixed and paraffin-embedded archival blocks, obtained between 1997 and 2009, were retrieved from the pathology departments of four hospitals: Nanfang Hospital affiliated to the Nanfang Medical University, Guangzhou General Hospital of the People's Liberation Army, Guangzhou Children's Hospital and Shaanxi Provincial People's Hospital. All sections had previously been diagnosed as positive for HL and were re-identified by two of our pathologists. The diagnosis of HL was established by finding H/RS cells within an appropriate background of reactive cells, according to the criteria of the latest WHO classification (4) and also based on morphological (H\&E section and immunophenotypic criteria (expression of CD20, CD43 and CD45RO antigen). The study was approved by the ethics committee of Shaanxi Provincial People's Hospital and written informed consent was obtained from the patients.

Immunohistochemistry (IHC). Paraffin sections were stained with MAbs (Dako, Carpinteria, CA, USA) against CD45RO antigen, CD20 antigen (L26), CD45RO antigen (UCHL1), CD15 antigen and CD30 antigen using a standard SP immunohistochemistry kit supplied by Beijing Zhongshan Biological Company (Beijing, China). LMP-1 was detected using a commercial cocktail of MAb against LMP1 (CS1-4, Dako), diluted at 1:200. The IHC procedure was performed as described previously (5). Diaminobenzidine (DAB) was used as a chromogen. Known EBV-positive HL cases were used as positive controls. Each case was tested a minimum of two or three times. 
Table I. Comparison of the EBV-positive rate observed using different detection methods in 59 cases of HL.

\begin{tabular}{lcrcc}
\hline & & \multicolumn{3}{c}{ Positive cases (\%) } \\
\cline { 3 - 4 } Type of HL & Cases (\%) & LMP1 & EBER1 & PCR (BamHI-W) \\
\hline LR & $30(50.8)$ & $21(70.0)$ & $22(73.3)$ & $24(80.0)$ \\
MC & $18(30.5)$ & $12(66.7)$ & $13(72.2)$ & $13(72.2)$ \\
NS & $8(13.6)$ & $4(50.0)$ & $3(37.5)$ & $4(50.0)$ \\
LD & $3(5.1)$ & $2(66.7)$ & $2(66.7)$ & $3(100)$ \\
Total & $59(100)$ & $39(66.1)$ & $40(67.8)$ & $44(74.6)$ \\
\hline
\end{tabular}

EBV, Epstein-Barr virus; LMP1, latent membrane protein 1; EBER1, Epstein-Barr virus early RNA; PCR, polymerase chain reaction; HL, Hodgkin's lymphoma; LR, lymphocyte-rich; MC, mixed cellularity; NS, nodular sclerosis; LD, lymphocyte depletion.
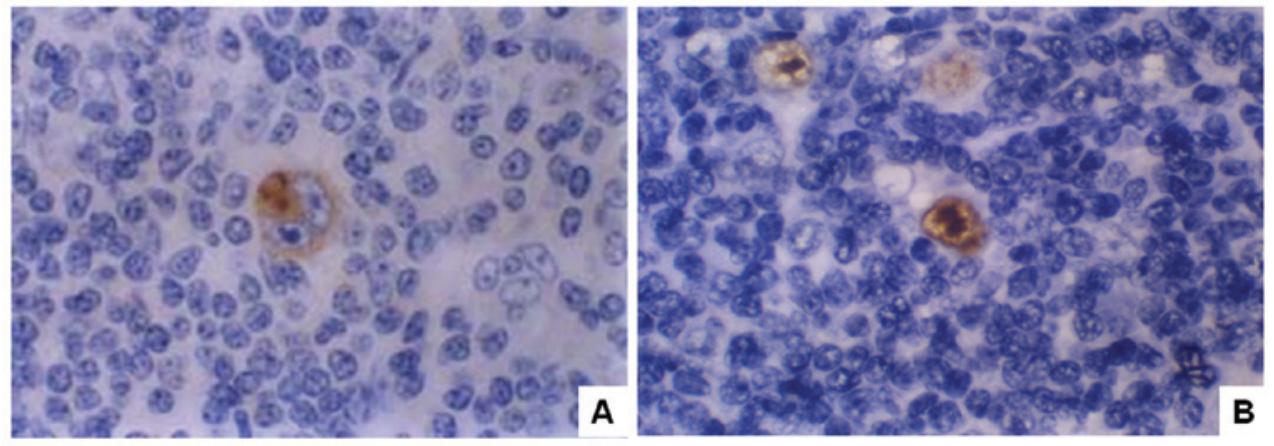

Figure 1. Two cases of Hodgkin's lymphoma in which H/RS cells expressed (A) EBV latent membrane protein 1 (LMP1) and (B) EBV-encoded early RNA1 (EBER1). DAB staining with H\&E counterstaining; magnification, x1,000. EBV, Epstein-Barr virus.

EBV-encoded RNA (EBER)1 ISH. EBER expression was detected using $20 \mathrm{bp}$ of doubled digoxigenin-labeled (5' end) oligonucleotide probes (antisense), 5'-ctacagccacacacgtctcc-3', designed by Primer 5.0 software, as the EBER 1 gene fragment (GeneBank gil16326314IAB065135.1, human herpesvirus 4 gene for EBER1 small RNA). The probe was synthesized and labeled by Takara Biotech Co. (Dalian, China). The ISH procedure used was described in the protocol of Boster Biotechnology Co. (Wuhan, China).

Briefly, the paraffin sections from each case were mounted on APES-treated glass slides, dewaxed and hydrated, predigested with pepsin (3\%) for 5-10 min and hybridized for 14-16 h with a probe concentration of $2 \mathrm{ng} / \mu \mathrm{l}$. The slides were washed with 2 X SSC, $0.5 \mathrm{X} \mathrm{SSC}$ and $0.2 \mathrm{X} \mathrm{SSC}$ for $15 \mathrm{~min}$ at $37^{\circ} \mathrm{C}$, blocked with BSA at $37^{\circ} \mathrm{C}$ for $30 \mathrm{~min}$, treated with biotinylated-rabbit antibodies against digoxin at $37^{\circ} \mathrm{C}$ for $60 \mathrm{~min}$ and washed with $0.5 \mathrm{M}$ PBS for $5 \mathrm{~min}$ four times. SABC was added at $37^{\circ} \mathrm{C}$ for $20 \mathrm{~min}$ and biotin-peroxidase at $37^{\circ} \mathrm{C}$ for $20 \mathrm{~min}$, then the sections were washed with $0.5 \mathrm{M}$ PBS for 5 min four times, dyed with DAB for 10 min and counter-stained with hematoxylin for $8 \mathrm{~min}$. Two known EBV-positive cases were routinely used as positive controls. Two slides treated without the probe were used as negative controls.

\section{PCR techniques}

DNA preparation. DNA was extracted from the formalinfixed paraffin-embedded tissues. Sections $(7 \mu \mathrm{m})$ were cut from each block and deparaffinized by three changes of xylene followed by ethanol washing. The samples were suspended in $50 \mu \mathrm{l}$ TE buffer, containing $10 \mathrm{mM}$ Tris-hydrochloric acid (pH 8.0) and $1 \mathrm{mM}$ EDTA (pH 8.0). The DNA was purified using Qiagen columns commercial kit (QIAamp DNA Mini kit; Qiagen, Shanghai, China), and when negative amplification for $\beta$-globin (housekeeping gene) was encountered, DNA was re-extracted.

PCR procedure. The first primer pair was a housekeeping gene $\beta$-globin: (PC04, 5'-caacttcatccacgttcacc-3'; GH20, 5'-gaagagccaaggacaggtac-3'; expected size $267 \mathrm{bp}$ ). The second was designed covering 253 bp of the EBV BamHI-W fragment, based on the DNA sequences of GenBank (forward, 5'-aatgggcgccattttgt-3' and reverse, 5'-tccctagaactgacaatt-3'). The PCR mixture contained $2 \mu 1$ template DNA, $2.0 \mu \mathrm{l} 10 \mathrm{X}$ PCR buffer [containing $100 \mathrm{mM}$ Tris- $\mathrm{HCl} \mathrm{pH} 9.0,100 \mathrm{mM}$ $\mathrm{KCl}, 80 \mathrm{mM}\left(\mathrm{NH}_{4}\right)_{2} \mathrm{SO}_{4}$ and $\left.0.1 \% \mathrm{NP} 40\right], 2.0 \mathrm{~mm} \mathrm{MgCl}_{2}$, $400 \mu \mathrm{M}$ dNTP mixture, 10 pmol of each primer and 1.5 units Taq Polymerase (Takara Bio, Inc.) in a final volume of $20 \mu \mathrm{l}$. The PCR procedure consisted of initial incubation for $5 \mathrm{~min}$ at $94^{\circ} \mathrm{C}, 30$ cycles of $94^{\circ} \mathrm{C}$ for $30 \mathrm{sec}$, then $56^{\circ} \mathrm{C}$ for $30 \mathrm{sec}$, $72^{\circ} \mathrm{C}$ for $30 \mathrm{sec}$ and a final extension at $72^{\circ} \mathrm{C}$ for $5 \mathrm{~min}$. PCR products were visualized under short-wavelength ultraviolet light following ethidium bromide staining of the agarose gels.

\section{Results}

Clinical data. There were 59 cases in total, 42 males and 17 females with a gender ratio of 2.5:1. The average age was 
Table II. Summaries of clinicopathological findings and EBV results.

\begin{tabular}{cccccc} 
Cases & Age/gender & Histological type LMP1 & EBER1 & PCR \\
\hline 2 & $57 / \mathrm{F}$ & MC & - & + & + \\
8 & $36 / \mathrm{M}$ & NS & - & - & + \\
11 & $19 / \mathrm{M}$ & LR & - & - & + \\
13 & $9 / \mathrm{M}$ & MC & - & + & + \\
15 & $49 / \mathrm{M}$ & LR & - & + & + \\
31 & $28 / \mathrm{F}$ & NS & + & - & + \\
33 & $21 / \mathrm{M}$ & LR & + & - & + \\
43 & $34 / \mathrm{M}$ & LR & - & + & + \\
56 & $9 / \mathrm{F}$ & LD & + & - & +
\end{tabular}

EBV, Epstein-Barr virus; M, male; F, female; LMP1, latent membrane protein 1; PCR, polymerase chain reaction; EBER1, Epstein-Barr virus-encoded RNA; LR, lymphocyte predominance; MC, mixed cellularity; NS, nodular sclerosis; LD, lymph depletion.

Table III. Comparison of EBER1 and LMP1 between the young and adult HL patients.

\begin{tabular}{llll}
\hline Age (years) & LMP1 $(\%)$ & EBER1 $(\%)$ & Total \\
\hline$<18$ & $26 / 27(96.3)^{\mathrm{a}}$ & $26 / 27(96.3)^{\mathrm{a}}$ & 27 \\
$>18$ & $13 / 32(40.6)^{\mathrm{b}}$ & $14 / 32(43.8)^{\mathrm{b}}$ & 32 \\
Total & $39 / 59(66.1)$ & $40 / 59(67.8)$ & 59 \\
\hline
\end{tabular}

${ }^{\mathrm{a}, \mathrm{b}}$ Significant difference of LMP1 and EBER1 between young and adult groups $(\mathrm{P}<0.01)$. EBER1, Epstein-barr virus encoded RNA; LMP1, latent membrane protein 1; HL, Hodgkin's lymphoma.

24.7 (range, 3-57) years old. The number of adolescent patients with HL was 27 (45.8\%), with 18 males and 9 females. Out of these cases, 30 were the lymphocyte predominance subtype (LR), 18 cases had mixed cellularity (MC), 8 cases had nodular sclerosis (NS) and 3 cases had the lymphocyte depletion (LD) subtype. These results are summarized in Table I.

LMPI and EBERl expression. The LMP1-positive cases demonstrated staining of the membrane and plasma of H/RS cells (Fig. 1A). Of the 59 cases, 39 (66.1\%) were shown to be LMP1 positive with the proportions of LR, MC, NS and LD subtypes revealed as $70.0(21 / 30), 66.7(12 / 18), 50.0(4 / 8)$ and $66.7 \%$ (2/3), respectively. By contrast, the H/RS nuclei were dyed using EBER1 ISH as described previously (4,5) (Fig. 1B). Of the 59 cases, $40(67.8 \%)$ were revealed to be EBER1positive using EBER1 ISH detection (Table I). Notably, among the 18 LMP1-positive cases, 3 weakly LMP1-positive cases (cases 31,33 and 56) could not be stained in the repeated EBER1 ISH attempts, while another 4 EBER1-positive cases (cases 2, 13, 15 and 43) were LMP1-negative (Table II). Significantly, we found that $26 / 27(96.3 \%)$ cases of young patients $(<18$ years old) were LMP1- and EBER1-positive, while, by contrast, only 13/32 (40.6\%) adult patients were positive for LMP1 and EBER1 (Table III).

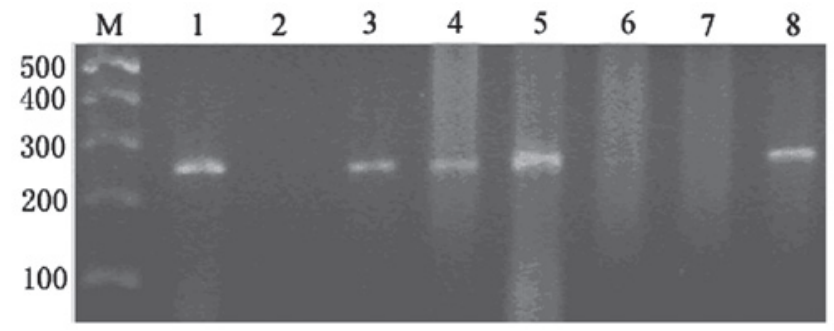

Figure 2. Results of PCR for 253 bp of the EBV BamHI-W fragment. M, marker; lane 1, positive control; lane 2, negative control; lanes 3-8, samples; lanes 3, 4, 5 and 8, positive; lanes 6 and 7, negative. PCR, polymerase chain reaction; EBV, Epstein-Barr virus.

EBV gene expression. Using PCR, 44 of 59 (74.6\%) cases were identified as positive for EBV BamHI-W fragment amplification, including 24/30 cases of LR, 13/18 cases of MC, 4/8 cases of NS subtype and $3 / 3$ cases of the LD subtype (Table I and Fig. 2). Seven cases (cases 2, 13, 15, 31, 33, 43 and 56) which were identified as either LMP1- or EBER1-negative, were all recognized as positive using the PCR detection method (Table II).

\section{Discussion}

Previous studies have shown that EBV examination may aid in making a correct diagnosis, developing treatment and finding an exact prognosis for EBV-associated diseases (3), thus efficient EBV detection is extremely important. In order to compare the detection rates of the EBV identification methods, three techniques, ISH for EBV early RNA1 (EBER1) sequences, IHC for LMP1 and PCR for EBV BamHI-W fragments, were used to detect the EBV status of $59 \mathrm{HL}$ cases from China using paraffin-embedded tissues.

The results revealed that $>66 \%$ of cases were identified as EBV-positive, which is a much higher percentage than that produced by Huang et al from Northern China (39\%, EBER ISH method) (6) and Fatima et al from Pakistan (60\%, EBV-LMP1 method) (4). The reason for this high incidence may mostly be as our cases include more young patients (27 out of 59 cases). Out of our 27 young cases, 26 (96.3\%) exhibited positive EBV results using either the LMP1 or EBER detection methods. It has been reported that the frequency of EBV-positive cases in children is extremely high (between 83 and $100 \%$ ) in developing countries (7). For example, there were $96.6 \%$ EBV-positive cases reported in Indian children and $90.3 \%$ in Brazilian children $(8,9)$, which we will examine later in this discussion.

Out of the three EBV detection methods employed, we found that the PCR method yields a higher EBV-positive detection rate $(74.6 \%, 44 / 59)$ than that of the LMP1 $(66.1 \%$, 39/59) or EBER1 $(67.8 \%, 40 / 59)$ methods (Table I). We also found two cases that were negative for LMP1 and EBER but that were positive using PCR detection (Table II). The reason for this may be that the target DNA is able to be amplified by thousands of times by the PCR procedure, thus the PCR method may have a higher sensitivity than the other two methods. However, the PCR method was unable to provide definite information concerning the cellular localization of the EBV-positive cells. 
As for the other two methods, it appeared that there was no significant difference between the LMP1 $(66.1 \%, 39 / 59)$ and EBER ISH $(67.8 \%, 40 / 59)$ techniques. Notably, we found that three samples that were LMP1-positive proved to be EBER1negative, while another four EBER1-positive cases were LMP1-negative (Table II). Repeated experiments revealed the same results. All these cases appeared EBV-positive when using the PCR detection method. Although these two methods were less sensitive than the PCR method, they provided more information about the localization of EBV-positive cells. We therefore recommend that at least two methods (PCR and either the LMP1 or EBER methods) be performed simultaneously to obtain the most accurate results for EBV infection detection.

In our experiment, we found that the majority of EBER1 and LMP1 expression occurs in an all-or-nothing manner in $\mathrm{H} / \mathrm{RS}$ cells, but that in certain cases only a small section of the focal H/RS cells were EBV-positive. One interpretation of this may be that some cells are destroyed during the sample preparation process (10-13). EBER is RNA that is preserved in paraffin-embedded tissue, which is easy to destroy during tissue preparation. To avoid false-negative rates, we recommend that several factors be considered prior to deciding that LMP1 or EBER expression is negative. Positive and negative controls should be performed during the experiments and all slide fields should be scanned in the diagnosis. For focal H/RS cells to be deemed EBV-positive, EBER and LMP1 detection methods should be simultaneously performed if possible.

EBV association in HL also depends on age, subtype of HL, location and other characteristics of the study population (3). Notably, almost all of our young cases $(26 / 27,96.3 \%)$ were LMP1- and EBER1-positive, which is a much higher percentage than that of African (68\%) (14), Brazilian (77\%) or Mexican (65\%) (15) cases and it is similar to results of Honduran (100\%) (16) and Peruvian (100\%) (17) cases. Our results support the view that an association of EBV with childhood HL may vary as a function of histological subtype and socio-economic status $(18,19)$. Concerning the HL subtype, most investigators regard the MC subtype as most frequently EBV-associated (70\%), followed by LR (50\%), NS (20\%) and LD $(<5 \%)$ subtypes $(3,19)$. Our results are slightly different, LR was observed to be the most frequent $(73.3 \%)$, followed by MC $(72.2 \%), \mathrm{LD}(66.7 \%)$ and NS (37.5\%) according to the results of our EBER detection. This difference may be attributed to the choice of HL cases.

In conclusion, in the present study, we compared three EBV detection methods in 59 cases of HL. The results demonstrated that the PCR method is the most sensitive of the three, but that it is unable to provide definite information with regard to cellular localization of the EBV-positive cells, while the LMP and EBER methods provided such information. We recommend that at least two methods be performed simultaneously to obtain the most accurate results for EBV infection.

\section{Acknowledgements}

Our thanks to Dr Ben-Chen Zhou. from the General Hospital of PLA and Dr Wang from Guangzhou Children's Hospital for their generosity with the HL samples.

\section{References}

1. Flavell KJ and Murray PG: Hodgkin's disease and the Epstein-Barr virus. Mol Pathol 53: 262-269, 2000.

2. Ambinder RF: Epstein-barr virus and Hodgkin lymphoma. Hematology Am Soc Hematol Educ Program 2007: 204-209, 2007.

3. Gulley ML, Glaser SL, Craig FE, et al: Guidelines for interpreting EBER in situ hybridization and LMP1 immunohistochemical tests for detecting Epstein-Barr virus in Hodgkin lymphoma. Am J Clin Pathol 117: 259-267, 2002.

4. Fatima S, Ahmed R and Ahmed A: Hodgkin lymphoma in Pakistan: an analysis of subtypes and their correlation with Epstein Barr virus. Asian Pac J Cancer Prev 12: 1385-1388, 2011.

5. Qi ZL, Zhao T, Zhou XH, Zhang JH, Han XQ and Zhu MG: Expressions of latent membrane protein 1, p53 and bcl-2 proteins and their significance in Hodgkin lymphoma. Di Yi Jun Yi Da Xue Xue Bao 23: 225-227, 2003.

6. Huang X, Nolte I, Gao Z, et al: Epidemiology of classical Hodgkin lymphoma and its association with Epstein Barr virus in Northern China. PLoS One 6: e21152, 2011.

7. Audouin J, Diebold J, Nathwani B, et al: Epstein-Barr virus and Hodgkin's lymphoma in Cairo, Egypt. J Hematop 3: 11-18, 2010.

8. Dinand V, Dawar R, Arya LS, et al: Hodgkin's lymphoma in Indian children: prevalence and significance of Epstein-Barr virus detection in Hodgkin's and Reed-Sternberg cells. Eur J Cancer 43: 161-168, 2007.

9. Barros MH, Hassan R and Niedobitek G: Disease patterns in pediatric classical Hodgkin lymphoma: a report from a developing area in Brazil. Hematol Oncol 29: 190-195, 2011.

10. Harris NL: Hodgkin's disease: classification and differential diagnosis. Mod Pathol 12: 159-175, 1999.

11. Murray PG, Billingham LJ, Hassan HT, et al: Effect of Epstein-Barr virus infection on response to chemotherapy and survival in Hodgkin's disease. Blood 94: 442-447, 1999.

12. Gulley ML: Molecular diagnosis of Epstein-Barr virus-related diseases. J Mol Diagn 3: 1-10, 2001.

13. Valente G, Secchiero P, Lusso P, et al: Human herpesvirus 6 and Epstein-Barr virus in Hodgkin's disease: a controlled study by polymerase chain reaction and in situ hybridization. Am J Pathol 149: 1501-1510, 1996.

14. Engel M, Essop MF, Close P, et al: Improved prognosis of Epstein-Barr virus associated childhood Hodgkin's lymphoma: study of 47 South African cases. J Clin Pathol 53: 182-186, 2000.

15. Zarate-Osorno A, Roman LN, Kingma DW, et al: Hodgkin's disease in Mexico: prevalence of Epstein-Barr sequences and correlation with histologic subtype. Cancer 75: 1360-1366, 1995.

16. Ambinder RF, Browing PJ, Lorenzana I, et al: Epstein-Barr virus and childhood Hodgkin's disease in Honduras and the United States. Blood 81: 462-467, 1993.

17. Chang KL, Albújar PF, Chen YY, et al: High prevalence of Epstein-Barr virus in the Reed-Sternberg cells of Hodgkin's disease occurring in Peru. Blood 81: 496-501, 1993.

18. Khan G, Norton AJ and Slavin G: Epstein-Barr virus in Hodgkin disease. Relation to age and subtype. Cancer 71: 3124-3129, 1993.

19. Glaser SL, Lin RJ, Stewart SL, et al: Epstein-Barr virusassociated Hodgkin's disease: epidemiologic characteristics in international data. Int J Cancer 70: 375-382, 1997. 